mgr inż. Marcin Kruś

dr inz. Pawet Kuligowski

dr inz. Rafal Cichy

Instytut Pojazdów Szynowych ,TABOR”

\title{
Symulacja komputerowa wytrzymałości platformy modułowego systemu transportu
}

\begin{abstract}
$W$ artykule zaprezentowano rezultaty symulacji numerycznej statycznej wytrzymatości konstrukcji nośnej platformy kolejowej stużacej do przewozu naczep drogowych $w$ modulowym systemie transportu kombinowanego, opracowanym w IPS , Tabor”- Poznań.

W pierwszej części przedstawiono ogólnie zagadnienia dotyczqce transportu intermodalnego w kontekśsie wymagań przepisów Technicznych Specyfikacji Interoperacyjności (TSI).

Następnie omówiono koncepcje projektowanego systemu transportu naczep drogowych pod względem wymagań i kryteriów wytrzymatościowych wedlug obowiqzujacych przepisów międzynarodowych. Zaprezentowano model obliczeniowy metody elementów skończonych (MES) opracowany dla konstrukcji nośnej wybranych elementów analizowanej platformy oraz przeglad wybranych wyników analizy wytrzymałości.

Prezentowane rezultaty sq wynikiem prac naukowo-badawczych realizowanych $w$ ramach projektu rozwojowego $n r$ R10-0065-10 „System transportu naczep drogowych na wózkach kolejowych w kombinowanym ruchu kolejowo-drogowym".
\end{abstract}

\section{WPROWADZENIE}

W założeniach transportowych dla Europy sformułowanych w Białej Księdze [1], w punkcie 2 p.t. „Wizja konkurencyjnego i zrównoważonego systemu transportu", postawiono między innymi następujace cele do osiagnięcia przez kraje UE: „Do 2030 r. 30\% drogowego transportu towarów na odległościach większych niż $300 \mathrm{~km}$ należy przenieść na inne środki transportu, np. kolej lub transport wodny, zaś do $2050 \mathrm{r}$. powinno to być ponad $50 \%$ tego typu transportu. Ułatwi to rozwój efektywnych, ekologicznych korytarzy transportowych".

Jednym $\mathrm{z}$ rozwiązań powyższych zagadnień jest transport kombinowany kolejowo-drogowy. Cele stawiane takiemu transportowi wymuszają rozwój prac badawczo-wdrożeniowych nad taborem oraz infrastruktura, które promuje i dofinansowuje UE.

W Instytucie Pojazdów Szynowych „TABOR” w Poznaniu od wielu lat realizowane sa projekty naukowo-badawcze nad nowoczesnymi rozwiązaniami środków transportu kolejowego, między innymi taboru dla ruchu kombinowanego kolejowo-drogowego, przystosowanego do przewozu naczep siodłowych.

\section{SYSTEMY INTERMODALNE A WYMA- GANIA TSI}

Transport towarów w systemie bimodalnym kolejowo - drogowym oznacza przewozy na znaczne odległości, czyli w przypadku Europejskim wiąże się to $\mathrm{z}$ przekraczaniem granic, co oznacza spełnienie wymagań stawianych pojazdom przez zarządy kolejowe różnych krajów europejskich. Tabor kombinowany stanowi, zatem jeden $\mathrm{z}$ lepszych przykładów zastosowania interoperacyjności w Europie.

Pojazdy intermodalne mają być wsparciem transportu drogowego. Ich opłacalność rośnie w zależności od odległości, na którą są przewożone towary. Konieczność ujednolicenia przepisów kolejowych na poziomie Technicznych Specyfikacji Interoperacyjności jest istotnym krokiem uwzględniającym możliwości zaistnienia transportu intermodalnego na skalę europejską. Pojazd intermodalny, który uzyska certyfikat zgodności UE w jednym kraju będzie mógł się poruszać po określonych liniach krajów będących członkami Unii Europejskiej. Uwzględnienie transportu naczep samochodowych po torach kolejowych w Technicznych Specyfikacjach Interoperacyjności stwarza nowe możliwości nie tylko dla samych pojazdów kolejowych, ale także dla rozwoju infrastruktury 
kolejowej oraz pracy bocznic i terminali przeładunkowych, które będa przystosowane do przeładunku systemów intermodalnych.

Realizacja przewozów na terenie wielu europejskich krajów oznacza spełnienie wymagań stawianych przez Narodowe Organy Bezpieczeństwa (NSA) poszczególnych państw. Wykorzystanie do realizacji przewozów korytarzy transportowych tworzonych w Europie oraz spełnienie przez pojazdy bimodalne wspólnych wymagań transportowych wydaje się być najlepszym rozwiązaniem, które należy wykorzystać do rozwoju tego systemu transportu. W obecnej sytuacji w Europie założyć można, że podstawą interoperacyjności dla pojazdów są wymagania Technicznych Specyfikacji Interoperacyjności (TSI). Pełne podporządkowanie pojazdów wymaganiom TSI umożliwiłoby poruszanie się po szlakach całej Europy, bez stosowania dodatkowych wymagan. To optymalne rozwiązanie wymagałoby zakończenia prac nad obowiązującymi TSI w postaci zamknięcia punktów otwartych i usunięcia przypadków szczególnych. Zgodnie z Polskim prawem [2] wymagania te powinny dotyczyć zarówno taboru jak i infrastruktury. Dla transportu bimodalnego właściwe jest zastosowanie wymagań TSI „Tabor kolejowy-wagony towarowe” [3].

Podejście prezentowane w TSI pokazuje, że wagony przeznaczone do przewozu naczep i systemy bimodalne powinny przede wszystkim spełniać kryteria, odnośnie wymagań konstrukcyjno-wytrzymałościowych, takie jak dla wagonów towarowych, a więc wynikające głównie z przepisów normy [5] dla kategorii FII z ograniczeniami w zakresie rozrządzania. Podstawowo są to analizy statyczne, zmęczeniowe, drgań własnych oraz stateczności. Z uwagi na szczególny charakter konstrukcji mają jednak postawione dodatkowe wymagania, które zostały opisane $\mathrm{w}$ TSI. Wymagania omówiono w artykule [4], gdzie przedstawiono szczegółowo dodatkowe wymagania stawiane pojazdom do transportu bimodalnego. W artykule [4] opisano szczegółowo dwa charakterystyczne dla transportu bimodalnego zagadnienia w aspekcie TSI „Tabor kolejowy-wagony towarowe”. Pierwszy dotyczy skrajni, a drugi obciążeń podczas hamowania lub podczas jazdy $\mathrm{z}$ popychaniem, bez ryzyka wykolejenia.

\section{MODULOWY SYSTEM TRANSPORTU}

W latach 2011-2013, w ramach realizacji projektu rozwojowego, opracowano koncepcję modułowego systemu transportu kombinowanego, którego podstawowe założenia omówiono w [6]. Układ systemu przedstawiono schematycznie na rys. 1 .

Podstawowym zespołem takiego rozwiązania jest platforma kolejowa, złożona $\mathrm{z}$ dwóch rozłącznych układów biegowych (przedniego 3 i tylnego 2), na której mocowana jest odpowiednio przystosowana naczepa drogowa 1 . Tak utworzony moduł ma możliwość połączenia z identycznym, za pomocą krótko spiętego urządzenia pociągowo-zderznego. Natomiast zestaw modułów ma możliwość połączenia z konwencjonalnym wagonem za pomocą typowego zderzaka i sprzęgu śrubowego. Załadunek naczepy na taki zespół jest możliwy na typowej bocznicy kolejowej po nieznacznym jej dostosowaniu.

Podstawowe dane techniczne wagonu:

masa całkowita wagonum $_{1}=53200 \mathrm{~kg}$,

masa własna naczepy $\mathrm{m}_{31}=8130 \mathrm{~kg}$,

masa ładunku na naczepiem ${ }_{32}=31000 \mathrm{~kg}$,

masa $\operatorname{ramym}_{\mathrm{r}}=4500 \mathrm{~kg}$,

masa adapteram $_{\mathrm{a}}=2570 \mathrm{~kg}$,

masa wózków $(2350 \mathrm{~kg}+2250 \mathrm{~kg}+2350 \mathrm{~kg}) \mathrm{m}_{2}=$ $6950 \mathrm{~kg}$,

długość ze zderzakamiL=29940 mm.

\section{SYMULACJA WYTRZYMALOŚCI KON- STRUKCJI \\ 4.1 Obiekt symulacji}

Obiektem badań symulacyjnych jest konstrukcja platformy modułowego systemu transportu naczep drogowych na wózkach kolejowych, ze szczególnym zwróceniem uwagi na ramę nośną tylnego układu jezdnego. Rama ta oparta jest na dwóch wózkach kolejowych dwuosiowych. Służy do przeniesienia obciążeń pionowych pochodzących od kół naczepy drogowej oraz kolejowych obciążeń wzdłużnych. Rama jest konstrukcją całkowicie spawana, którą tworzy belka grzbietowa, poprzecznice i ostojnice stanowiące platformę dla kół naczepy. Oparcie ramy realizowane jest za pomocą stosów gumowych z przekładkami metalowymi. Schemat obciążenia poszczególnych elementów zestawu przedstawiono na rysunku 2 .

Rys. 1. Układ systemu - widok ogólny [6]

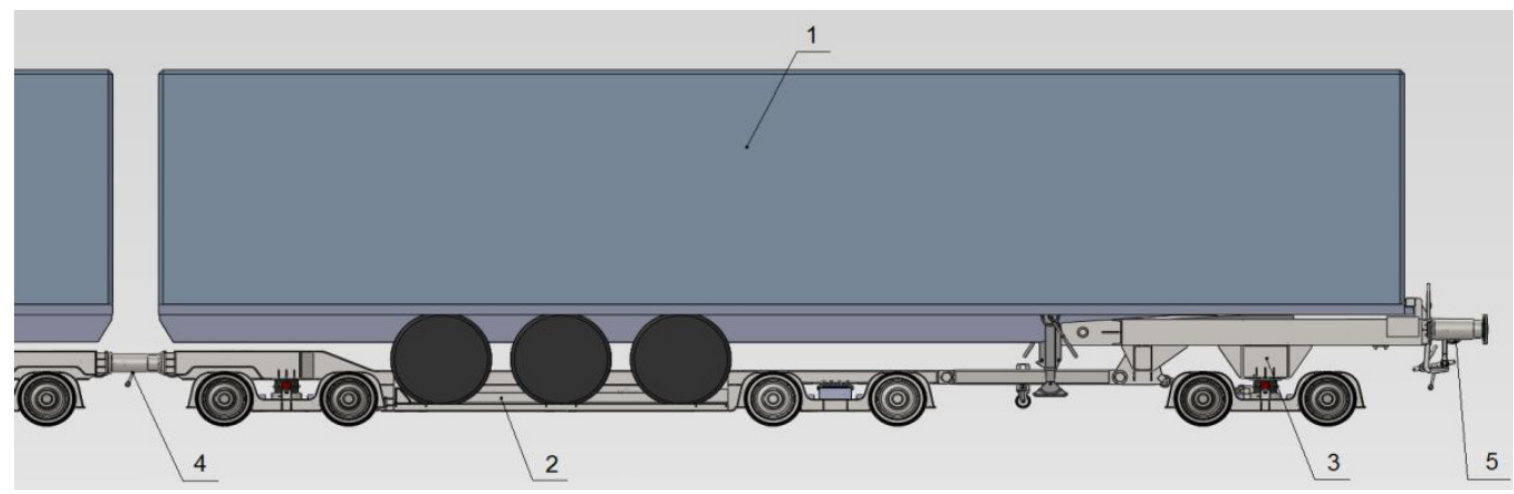



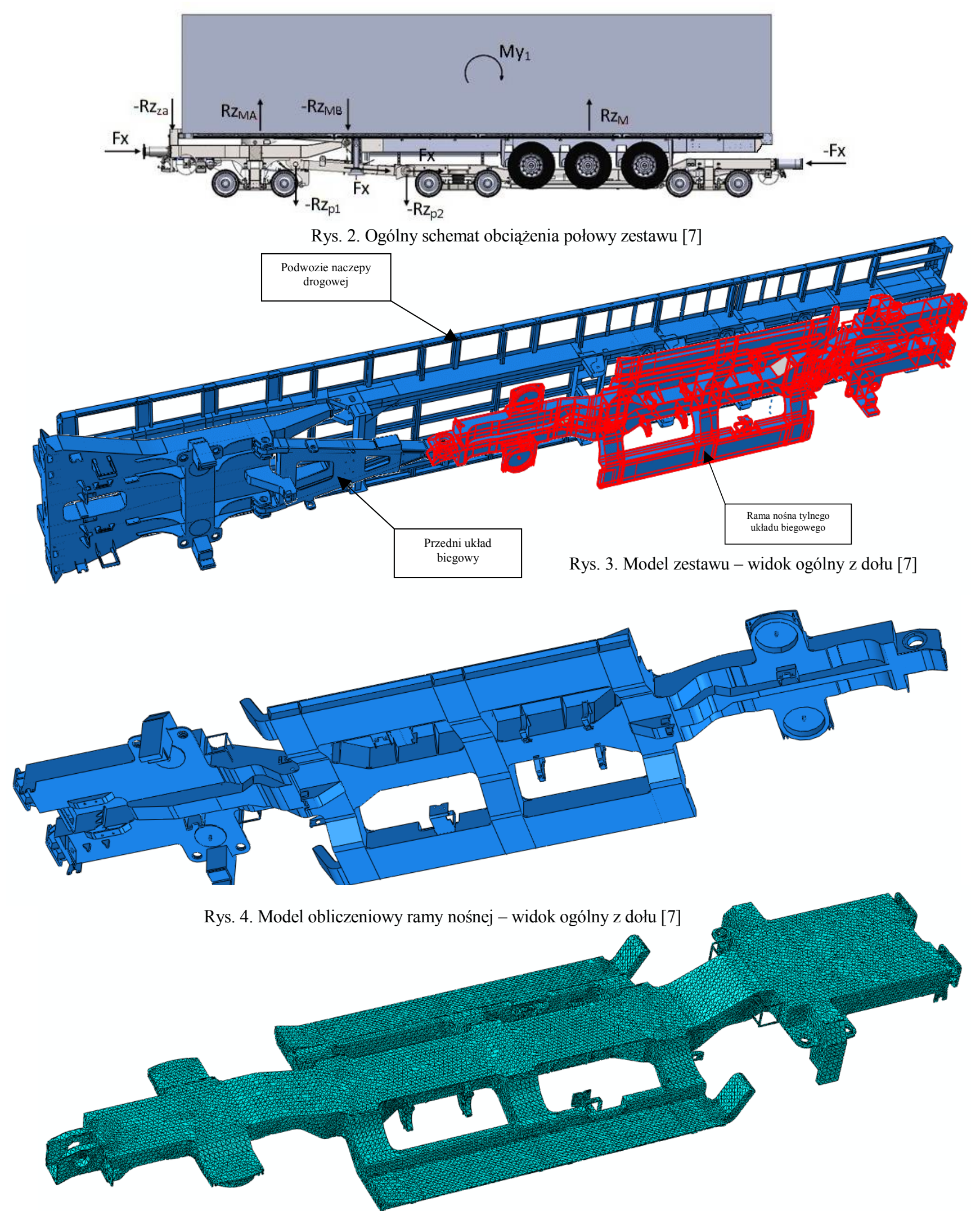

Rys. 5. Podział modelu obliczeniowego ramy nośnej na elementy skończone - widok ogólny z góry [7]

Widok ogólny modelu platformy $\mathrm{z}$ naczepą (bez wózków), z wyróżnioną ramą nośną tylnego układu biegowego pokazano na rys. 3 .

Wymiary geometryczne i kształty przyjęto na podstawie dokumentacji konstrukcyjnej. W modelu obliczeniowym uwzględniono wszystkie elementy mające wpływ na pracę układu nośnego oraz właściwe wprowadzenie i odebranie analizowanych obciążeń. Ze względu na sposób obciążenia i oddziaływania ramy nośnej na inne elementy pojazdu, analizę wykonano na modelu uwzględniającym wszystkie podzespoły nośne pojazdu. W modelu zastosowano elementy typu zawias (hinge) w miejscu mocowania dyszla $\mathrm{z}$ adapterem $\mathrm{i}$ dyszla $\mathrm{z}$ ramą oraz adaptera $\mathrm{z}$ 
naczepą w miejscu połączenia $\mathrm{z}$ siodłem naczepy. Pomiędzy skrajną częścią naczepy i adaptera ustawiono kontakt. Pomiędzy kołami naczepy zastosowano sztywne elementy typu belkowego (beam). W modelu obliczeniowym uwzględniono sztywność w kierunku pionowym opony i odbijaka na poziomie $2 \mathrm{kN} / \mathrm{mm}$. W obliczeniach przyjęto układ współrzędnych, gdzie oś $\mathrm{x}$ wyznacza kierunek jazdy, y - prostopadły do osi toru, $\mathrm{z}$ - pionowy.

W modelu naczepy zastosowano czworokatne, ośmiowęzłowe elementy płytowo-powłokowe S8R, natomiast $\mathrm{w}$ modelu obliczeniowym adaptera $\mathrm{i}$ ramy zastosowano elementy bryłowe C3D10.

Ze względu na fakt, że analizę wyników badań symulacyjnych, w niniejszym artykule, ograniczono tylko dla wyróżnionej na rys. 3 ramy nośnej, jej model obliczeniowy przedstawiono na rys. 4, a podział na elementy skończone na rys. 5 .

\subsection{Zakres symulacji - dobór obciążeń oraz kryte- ria oceny}

Rodzaje obciążeń oraz kryteria wytrzymałości dla statycznej symulacji przyjęto zgodnie z wymaganiami zawartymi w normie PN-EN 126632:2010 [5]. Określono przypadki superpozycji konieczne do przeprowadzenia oceny wytrzymałości statycznej konstrukcji nadwozia, a zestawiono je poniżej:

a) ściskanie siłą $1200 \mathrm{kN}$ (po $600 \mathrm{kN}$ na jeden zderzak) przyłożoną $\mathrm{W}$ osi zderzaków i obciążenie pionowe $1,0 \times \mathrm{g} \times\left(\mathrm{m}_{31}+\mathrm{m}_{\mathrm{r}}+\right.$ $\mathrm{m}_{\mathrm{a}}$ ),

b) ściskanie siłą $400 \mathrm{kN}$ przyłożoną w osi zderzaków po przekątnej wagonu i obciążenie pionowe $1,0 \times \mathrm{g} \times\left(\mathrm{m}_{31}+\mathrm{m}_{\mathrm{r}}+\mathrm{m}_{\mathrm{a}}\right)$,

c) rozciaganie siłą $1000 \mathrm{kN}$ przyłożoną w rejonie opory sprzęgu śrubowego i obciążenie pionowe $1,0 \times \mathrm{g} \times\left(\mathrm{m}_{31}+\mathrm{m}_{\mathrm{r}}+\mathrm{m}_{\mathrm{a}}\right)$,

d) obciążenie pionowe $1,0 \times \mathrm{g} \times\left(\mathrm{m}_{31}+\mathrm{m}_{32}+\right.$ $\left.\mathrm{m}_{\mathrm{r}}+\mathrm{m}_{\mathrm{a}}\right)$,

e) jednoczesne działanie obciążeń wymienionych w pkt. a), i c) i statycznego obciążenia pionowego $1,0 \times \mathrm{g} \times\left(\mathrm{m}_{31}+\mathrm{m}_{32}+\mathrm{m}_{\mathrm{r}}+\right.$ $\left.\mathrm{m}_{\mathrm{a}}\right)$.

f) sprawdzenie wsporników wyposażenia przy maksymalnym przyspieszeniu wzdłużnym $5 \mathrm{~g}$ i obciążenie pionowe $1,0 \times \mathrm{g} \times\left(\mathrm{m}_{31}+\right.$ $\left.\mathrm{m}_{32}+\mathrm{m}_{\mathrm{r}}+\mathrm{m}_{\mathrm{a}}\right)$.

Założono, że głównym materiałem konstrukcyjnym na podstawowy ustrój nośny jest stal typu S355. Wartości naprężeń dopuszczalnych dla statycznego kryterium wytrzymałości zgodnie z normą [5] nie moga przekraczać granicy plastyczności materiału ze współczynnikiem bezpieczeństwa $\mathrm{s}=1.15$. W tym przypadku $\sigma_{\text {dop }}=\mathrm{R}_{\mathrm{e}} / 1.15=355 / 1.15=309 \mathrm{MPa}$.
Analizę wytrzymałości ustroju nośnego wagonu wykonano metodą elementów skończonych (MES) wykorzystując system obliczeniowy ABAQUS.

\subsection{Wyniki analizy i ich omówienie}

Ze względu na obszerny zakres analizowanych przypadków obciążeń uwzględnionych w przeprowadzonych badaniach symulacyjnych, w niniejszym opracowaniu omówiono tylko wyniki dla wybranych obciążeń, powodujących powstanie maksymalnych naprężeń i odkształceń. Rozkład naprężeń zredukowanych i przemieszczeń dla obciążenia ściskającego, pionowego oraz ich superpozycji pokazano na rys. 611.

Uzyskane, w trakcie badań symulacyjnych wytrzymałości konstrukcji ramy modułowego systemu transportu, naprężenia zredukowane generalnie nie przekraczają wartości dopuszczalnych określonych zgodnie z normą [5]. Wyjątek stanowią lokalne koncentracje naprężeń, których można w zadawalający sposób uniknąć poprzez zastosowanie w tych rejonach materiału o lepszych własnościach mechanicznych (np. o wyższej granicy plastyczności $\mathrm{Re})$.

Wartości przemieszczeń w kierunku pionowym osiagają maksymalna wartość dla przypadku superpozycji obciążenia pionowego i ściskającego, ale nie przekraczają wartości odpowiadających $2 \%$ bazy ramy nośnej $(2 \mathrm{a}=5800 \mathrm{~mm})$. Graniczna wartość powinna wynosić nie więcej niż 3\%o rozstawu czopów.

\section{PODSUMOWANIE}

Przeprowadzona wstępna symulacja statycznej wytrzymałości konstrukcji platformy modułowego systemu transportu wykazuje, że wymagane normą [5] kryteria oceny zostały spełnione. Zaproponowane rozwiązania konstrukcyjne dla innowacyjnego systemu transportu kombinowanego naczep samochodowych na wózkach kolejowych, zapewniają wystarczającą wytrzymałość na przeniesienie obciążeń powstających w eksploatacji.

Pozytywna ocena wytrzymałości proponowanego systemu, w powiązaniu $\mathrm{z}$ niezaprzeczalnymi zaletami, głównie w zakresie kosztów produkcji i eksploatacji zarówno taboru jak i wymaganej infrastruktury, gwarantuje możliwość rozwoju oraz zastosowania tego typu rozwiązania w transporcie kombinowanym naczep na wózkach kolejowych. 

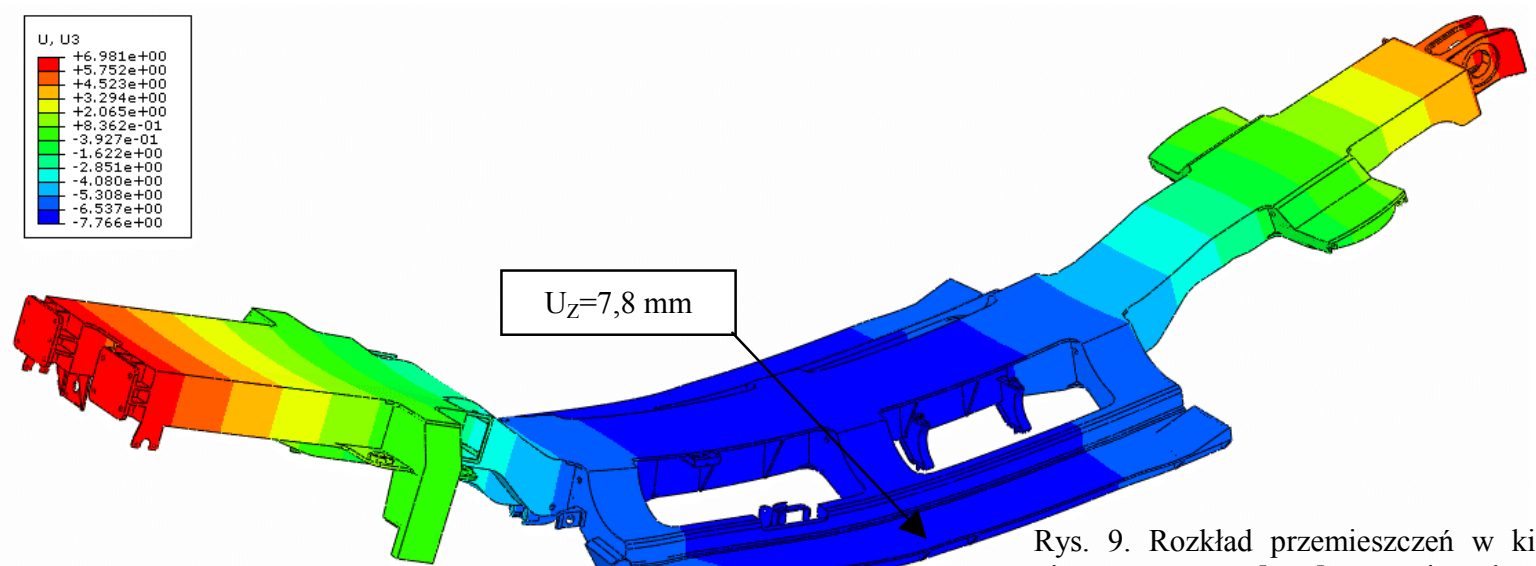

Rys. 9. Rozkład przemieszczeń w kierunku pionowym $\mathrm{U}_{\mathrm{Z}} \mathrm{w}[\mathrm{mm}]$ powstających $\mathrm{w}$ ramie podczas obciążenia pionowego $1,0 \times \mathrm{g} \times\left(\mathrm{m}_{31}+\right.$ $\mathrm{m}_{32}+\mathrm{m}_{\mathrm{r}}+\mathrm{m}_{\mathrm{a}}$ ) - widok ogólny z góry. Skala odkształcenia 250:1.

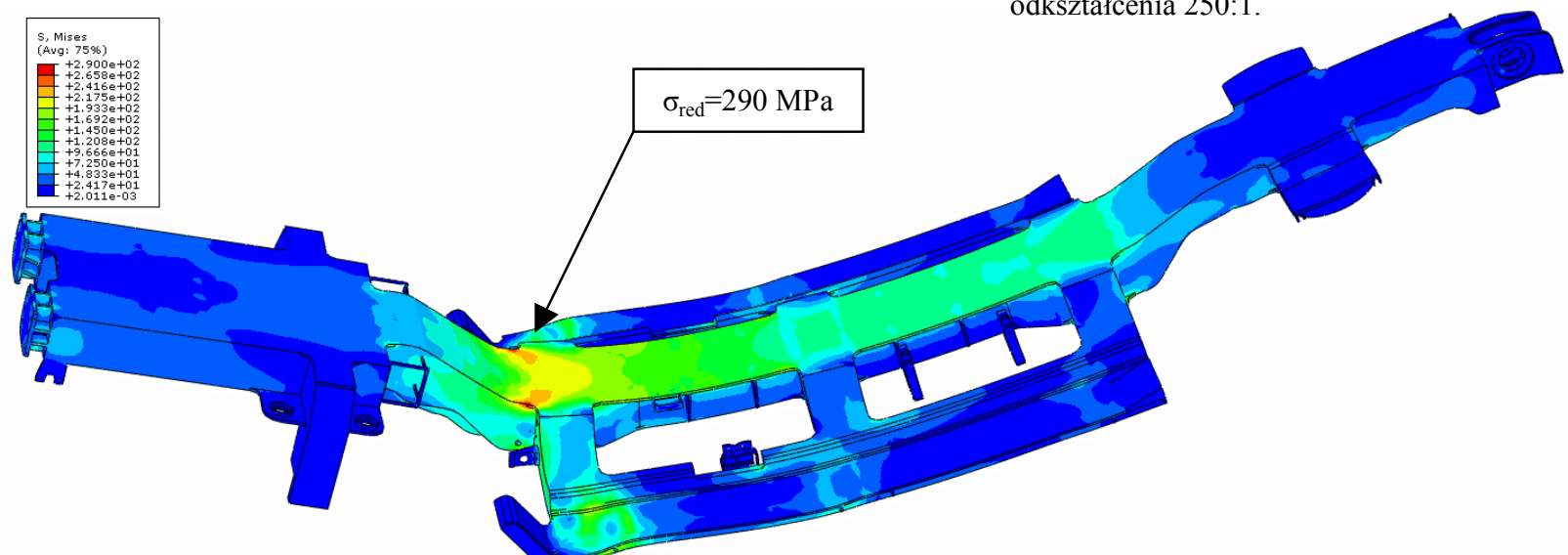

Rys. 10. Rozkład naprężeń zredukowanych w [MPa] powstających w ramie podczas superpozycji ściskania zestawu modułowego siłą $1200 \mathrm{kN}$ w osi zderzaków i obciążenia pionowego $1,0 \times \mathrm{g} \times\left(\mathrm{m}_{31}+\right.$ $\mathrm{m}_{32}+\mathrm{m}_{\mathrm{r}}+\mathrm{m}_{\mathrm{a}}$ ) - widok ogólny $\mathrm{z}$ góry. Skala odkształcenia 180:1.

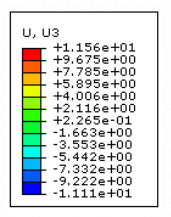

$\mathrm{U}_{\mathrm{Z}}=11,1 \mathrm{~mm}$

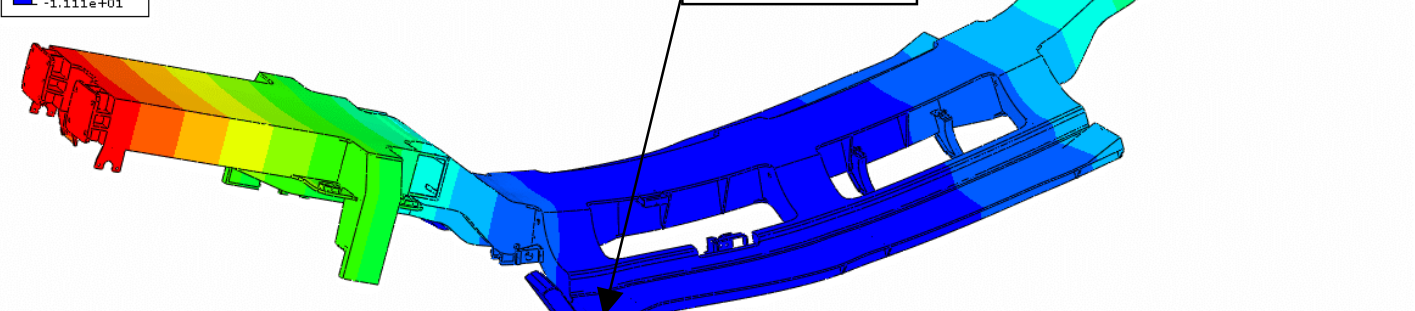

Rys. 11. Rozkład przemieszczeń w kierunku pionowym UZ w [mm] powstających $\mathrm{w}$ ramie podczas superpozycji ściskania zestawu modułowego siłą $1200 \mathrm{kN}$ w osi zderzaków i obciążenia

\section{Bibliografia}

[1] Biała Ksiega. Plan utworzenia jednolitego europejskiego obszaru transportu - dażenie do osiagnięcia konkurencyjnego $i$ zasobooszczędnego systemu transportu. Bruksela 28.03.2011. Wersja ostateczna.

[2] Ustawa z dnia 28 marca 2003 r. o transporcie kolejowym (Dz. U. 2003 r. Nr 86 poz 789) z późniejszymi zmianami,

[3] Decyzja Komisji z dnia 28 lipca 2006 r. dotyczqca technicznej specyfikacji dla interoperacyjności odnoszqcej się do podsystemu ",tabor kolejowy - wagony towarowe" transeuropejskiego systemu kolei konwencjonalnych

[4] Cichy R., Medwid M.: Wymagania TSI „,Tabor kolejowy wagony towarowe" do przewozu naczep drogowych $w$ systemach intermodalnych. Pojazdy Szynowe 3/2012. pionowego $1,0 \times \mathrm{g} \times\left(\mathrm{m}_{31}+\mathrm{m}_{32}+\mathrm{m}_{\mathrm{r}}+\mathrm{m}_{\mathrm{a}}\right)-$ widok ogólny $\mathrm{z}$ góry. Skala odkształcenia 180:1.

[5] PN-EN 12663-2: 2010. Kolejnictwo - Wymagania konstrukcyjno - wytrzymałościowe dotyczqce pudet kolejowych pojazdów szynowych - Część 2: Wagony towarowe.

[6] Madej J., Medwid M., Cichy R., Jakuszko W., Nowaczyk T.: Modułowy system transportu naczep siodtowych na wózkach kolejowych $w$ ruchu kombinowanym kolejowo-drogowym. Pojazdy Szynowe 2/2013.

[7[ OR 10368: Sprawozdanie z obliczeń wytrzymałości ramy nośnej tylnego ukladu jezdnego nadwozia systemu transportu naczep drogowych na wózkach kolejowych $w$ ruchu kombinowanym kolejowo- drogowym, Praca niepublikowana. IPS ,TABOR”-Poznań, maj 2013. 